\title{
Masticatory musculature of the African mole-rats (Rodentia: Bathyergidae)
}

\author{
Philip G Cox ${ }^{\text {Corresp., } 1}$, Chris G Faulkes ${ }^{2}$, Nigel C Bennett ${ }^{3}$ \\ 1 Department of Archaeology and Hull York Medical School, University of York, York, United Kingdom \\ 2 School of Biological and Chemical Sciences, Queen Mary University of London, London, United Kingdom \\ 3 Mammal Research Institute, Department of Zoology and Entomology, University of Pretoria, Pretoria, South Africa \\ Corresponding Author: Philip G Cox \\ Email address: philip.cox@hyms.ac.uk
}

The Bathyergidae, commonly known as blesmols or African mole-rats, is a family of rodents well-known for their subterranean lifestyle and tunnelling behaviour. Four of the five extant bathyergid genera (Cryptomys, Fukomys, Georyhus and Heliophobius) are chisel-tooth diggers, that is they dig through soil with their enlarged incisors, whereas the remaining genus (Bathyergus) is a scratch-digger, only using its forelimbs for burrowing. Heterocephalus glaber, the naked mole-rat, is also a chisel-tooth digger and was until recently included within the Bathyergidae (as the most basally branching genus), but has now been placed by some researchers into its own family, the Heterocephalidae. Given the importance of the masticatory apparatus in habitat construction in this group, knowledge and understanding the morphology and arrangement of the jaw-closing muscles in Bathyergidae is vital for future functional analyses. Here, we use diffusible iodine-based contrast-enhanced microCT to reveal and describe the muscles of mastication in representative specimens of each genus of bathyergid mole-rat and to compare them to the previously described musculature of the naked mole-rat. In all bathyergids, as in all rodents, the masseter muscle is the most dominant component of the masticatory musculature. However, the temporalis is also a relatively large muscle, a condition normally associated with sciuromorphous rodents. Unlike their hystricomorphous relatives, the bathyergids do not show an extension of the masseter through the infraorbital foramen on to the rostrum (other than a very slight protrusion in Cryptomys and Fukomys). Thus, morphologically, bathyergids are protrogomorphous, although this is thought to be secondarily derived rather than retained from ancestral rodents. Overall, the relative proportions of the jaw-closing muscles were found to be fairly consistent between genera except in Bathyergus, which was found to have an enlarged superficial masseter and relatively smaller pterygoid muscles. It is concluded that these differences may be a reflection of the behaviour of Bathyergus which, uniquely in the family, does not use its 
incisors for digging. 
1 Title: Masticatory musculature of the African mole-rats (Rodentia: Bathyergidae)

2 Authors: Philip G. Cox ${ }^{1}$, Chris G. Faulkes ${ }^{2}$, Nigel C. Bennett ${ }^{3}$

$3{ }^{1}$ Department of Archaeology and Hull York Medical School, University of York, UK

$4 \quad{ }^{2}$ School of Biological and Chemical Sciences, Queen Mary University of London, UK

$5 \quad{ }^{3}$ Mammal Research Institute, Department of Zoology and Entomology, University of Pretoria,

6 South Africa

7

8 Corresponding author: Philip G. Cox

9 Address: PalaeoHub, University of York, Wentworth Way, Heslington, York, YO10 5DD

Telephone: +441904321744

11 Email: philip.cox@hyms.ac.uk 
well-known for their subterranean lifestyle and tunnelling behaviour. Four of the five extant bathyergid genera (Cryptomys, Fukomys, Georyhus and Heliophobius) are chisel-tooth diggers, that is they dig through soil with their enlarged incisors, whereas the remaining genus (Bathyergus) is a scratch-digger, only using its forelimbs for burrowing. Heterocephalus glaber, the naked mole-rat, is also a chisel-tooth digger and was until recently included within the Bathyergidae (as the most basally branching genus), but has now been placed by some researchers into its own family, the Heterocephalidae. Given the importance of the masticatory apparatus in habitat construction in this group, knowledge and understanding the morphology and arrangement of the jaw-closing muscles in Bathyergidae is vital for future functional analyses. Here, we use diffusible iodine-based contrast-enhanced microCT to reveal and describe the muscles of mastication in representative specimens of each genus of bathyergid mole-rat and to compare them to the previously described musculature of the naked mole-rat. In all bathyergids, as in all rodents, the masseter muscle is the most dominant component of the masticatory musculature. However, the temporalis is also a relatively large muscle, a condition normally associated with sciuromorphous rodents. Unlike their hystricomorphous relatives, the bathyergids do not show an extension of the masseter through the infraorbital foramen on to the rostrum (other than a very slight protrusion in Cryptomys and Fukomys). Thus, morphologically, bathyergids are protrogomorphous, although this is thought to be secondarily derived rather than retained from ancestral rodents. Overall, the relative proportions of the jaw-closing muscles were found to be fairly consistent between genera except in Bathyergus, which was found to have an enlarged superficial masseter and relatively smaller pterygoid muscles. It is concluded that these differences may be a reflection of the behaviour of Bathyergus which, uniquely in the family, does not use its incisors for digging.

Keywords: Masticatory muscles; diceCT; virtual reconstruction; Bathyergidae; Rodentia 


\section{Introduction}

The comparative anatomy of the masticatory, or jaw-closing, muscles in rodents has been a wellstudied topic over many years (e.g. Wood, 1965; Turnbull, 1970; Woods, 1972; Woods \& Howland, 1979; Woods \& Hermanson, 1985; Ball \& Roth, 1995; Thorington \& Darrow, 1996; Druzinsky, 2010; Cox \& Jeffery, 2011, 2015). Early classifications of rodents were based on masticatory muscle anatomy (Brandt, 1855), although modern phylogenies based on molecular data (Blanga-Kanfi et al., 2009; Fabre et al., 2012; Swanson et al., 2019) have shown many of the myological similarities between taxa to be the result of convergent evolution rather than shared evolutionary history. Nonetheless, the highly specialised feeding system in rodents (including enlarged, ever-growing incisors and a lower jaw that can move antero-posteriorly with respect to the cranium) has ensured that the morphology of the jaw adductor muscles remains a relevant research topic in the field of functional morphology.

One group of rodents that is particularly interesting with regard to the jaw-closing muscles is the Bathyergidae, a family of subterranean rodents known as blesmols or African mole-rats. The family comprises at least 21 species (Van Daele et al., 2007; Faulkes et al., 2011, 2017; Burgin et al., 2018; Visser, Bennett \& Jansen van Vuuren, 2019) in five genera - Bathyergus, Cryptomys, Fukomys, Georychus and Heliophobius - all found in sub-Saharan Africa. A sixth monospecific genus, Heterocephalus (the naked mole-rat), was until recently also included within the Bathyergidae. However, it has been proposed (Patterson \& Upham, 2014) that Heterocephalus glaber should be placed in its own family, the Heterocephalidae (Landry, 1957) based on the depth of the split from other bathyergids (c. 31.2 Ma) and a number of morphological characters. Nevertheless, it is important to note that from an evolutionary perspective the two families are still united as a monophyletic superfamily, the Bathyergoidea (Fig. 1). This division of mole-rats into two families is not universally supported (e.g. Visser, Bennett \& Jansen van Vuuren, 2019), but nonetheless has been reflected in a number of recent mammalian taxonomies (Wilson, 
94 Lacher \& Mittermeier, 2016; Burgin et al., 2018). Accepting this classification, the Bathyergidae 95 first diversified in the early Miocene, around 17.9 Ma (Patterson \& Upham, 2014) with the earliest known fossils dating from this time as well (Mein \& Pickford, 2008).

African mole-rats are highly specialised for a fossorial lifestyle, spending much of their life underground in complex networks of burrows (Bennett \& Faulkes, 2000). Five of the six genera (Cryptomys, Fukomys, Georychus, Heliophobius and Heterocephalus) are chisel-tooth diggers that dig tunnels with their incisors, whereas the remaining genus, Bathyergus, is a scratch digger, only using its limbs for digging (Stein, 2000). Chisel-tooth digging blesmols share a number of morphological adaptations to this behaviour, such as enlarged incisors, taller and wider skulls, enlarged temporal fossae, and longer jaws (McIntosh \& Cox, 2016a,b; Samuels \& Van Valkenburgh, 2016). These modifications have been shown to facilitate the production of high bite forces and wide gapes, both necessary for digging with the incisors (McIntosh \& Cox, 2016a).

Despite the well-known osteological adaptations to digging seen in the bathyergid masticatory system, there are comparatively few in-depth studies of the jaw muscle anatomy of blesmols in the published literature. Tullberg (1899), in his large survey of rodent and lagomorph anatomy, illustrated some of the more superficial muscles of Georychus capensis, Cryptomys hottentotus and Bathyergus suillus. Boller (1970) and Van Daele, Herrel \& Adriaens (2009) provide more detailed descriptions, but only of Cryptomys hottentotus and Fukomys species respectively. A study of subterranean rodents published by Morlok (1983) has a much broader coverage, including all bathyergid genera except Fukomys, which was split more recently from Cryptomys (Kock et al., 2006). However, the only detailed descriptions and figures of masticatory musculature in this work are of Cryptomys. Most recently, the masticatory musculature of Heterocephalus glaber (now removed from the Bathyergidae as mentioned above) was described by Cox \& Faulkes (2014) using digital dissection. That is, the jaw-closing musculature was visualised and virtually reconstructed via diffusible iodine-based contrast-enhanced computed tomography (diceCT). This methodology, developed over the last decade (Metscher, 2009; Jeffery et al., 2011; Gignac \& Kley, 2014; Gignac et al., 2016), uses iodine staining to increase the radiodensity of soft tissues and render them visible in CT scans. The technique is a useful 
125 complement to physical dissection, particularly when studying small specimens with complex,

126 layered musculature.

127

128 The aim of this study is to describe the jaw-closing musculature of all five currently recognised

129 genera of bathyergid mole-rats, in order to facilitate comparisons between them and also with the

130 masticatory musculature of the closely related naked mole-rat. It is hypothesised that all chisel-

131 tooth digging bathyergids have a similar arrangement of jaw adductor muscles, owing to the

132 strong functional constraint of needing to produce a high bite force at a wide gape (McIntosh \&

133 Cox, 2016a). Furthermore, it is hypothesised that the relative proportions of the jaw adductors in

134 chisel-tooth digging bathyergids are similar to those previously described in the naked mole-rat

135 (Cox \& Faulkes, 2014), owing to its similar mode of digging and its shared common ancestor

136 with Bathyergidae. Finally, it is hypothesised that blesmols of the genus Bathyergus differ from

137 other bathyergid genera in the relative proportions of their jaw-closing muscles, as these taxa are

138 scratch diggers that do not use their incisors to construct burrows (Stein, 2000). In particular, the

139 temporalis has been proposed to be particularly important in chisel-tooth digging (Samuels \&

140 Van Valkenburgh, 2009; McIntosh \& Cox, 2016a), so this muscle is hypothesised to be

141 relatively smaller in Bathyergus.

142

143 Materials and Methods

144 Sample and scanning

145 Five ethanol-preserved heads of bathyergid mole-rats were obtained from collections originating

146 from the University of Pretoria. The work was approved by the animal ethics committee at the

147 University of Pretoria AUCC 030110-002 and AUCC 040702-015. The specimens represented

148 one species from each of the five currently recognised genera of Bathyergidae: Bathyergus

149 suillus, Cryptomys hottentotus, Fukomys mechowi, Georychus capensis and Heliophobius

150 argenteocinereus. As ethanol is known to reduce the efficacy of diceCT (Gignac et al., 2016),

151 the concentration of the preserving fluid was gradually reduced from $70 \%$ ethanol down to

152 distilled water over a period of 2 weeks. After another week in distilled water, the specimens

153 were immersed in 4\% phosphate-buffered formaldehyde solution. Finally, the specimens were

154 transferred to a 7.5\% solution of iodine-potassium iodide in formaldehyde for 3 months. The

155 stained specimens were scanned using microCT at the Cambridge Biotomography Centre, 
156 University of Cambridge. The scans were performed at $164 \mathrm{kV}$ and $165 \mu \mathrm{A}(175 \mathrm{kV}$ and $156 \mu \mathrm{A}$

157 for Bathyergus suillus), with a $0.5 \mathrm{~mm}$ copper filter and a beryllium target. Voxels were

158 isometric with dimensions between 0.026 and $0.046 \mathrm{~mm}$. Further scanning details are given in

159 Table S1. The diceCT stacks are archived and available from www.morphosource.org (the DOI

160 of each stack is given in Table S1).

161

162

Digital reconstruction

163 Scans were imported as stacked TIFF files to Avizo 9.2 Lite (Thermo Fisher Scientific,

164 Waltham, MA, USA) and the jaw adductor muscles of one side of the head were reconstructed.

165 The side of the head chosen for reconstruction differed between specimens and was based on the

166 quality of the staining and scanning in the left and right muscles. The muscles that were digitally

167 reconstructed comprised the superficial masseter, deep masseter, zygomaticomandibularis,

168 temporalis, medial pterygoid and lateral pterygoid, following the nomenclature of Cox \& Jeffery

169 (2011) and Cox \& Faulkes (2014). Automatic thresholding of masticatory muscles was not

170 possible owing to insufficient contrast difference between bone and muscle, and therefore the

171 muscles were reconstructed using manual painting of selected slices and interpolation between

172 them. Each muscle volume was subjected to a single application of the 'smooth labels' algorithm

173 within the Avizo segmentation editor (size, 4; mode, 3D volume), and the volume of each muscle

174 was recorded. Muscle masses were calculated from volumes assuming a muscle density value of

$1751.0564 \mathrm{gcm}^{-3}$ (Murphy \& Beardsley, 1974), although absolute mass values should be treated with

176 caution as both iodine staining and formalin preservation are known to lead to soft tissue

177 shrinkage (Vickerton, Jarvis \& Jeffery, 2013). The percentage contribution of each muscle to

178 total adductor muscle mass was also calculated for each specimen. In addition to the digital

179 dissections, three of the specimens were also physically dissected (Bathyergus, Cryptomys,

180 Georychus). Digital and physical dissections were compared both quantitatively (relative

181 muscles masses) and qualitatively to ensure that muscle attachment sites and boundaries between

182 muscle layers had been correctly identified in the diceCT scans. As congruence between the

183 dissection methods was good (attachment sites correctly identified, relative muscle masses

184 within 4\%), digital dissection was deemed to be an accurate reflection of the morphology. 
186 The reconstructed muscles were visualised by aligning them with a virtually reconstructed skull

187 and mandible. Because scans of the unstained specimens were not available, and $\mathrm{I}_{2} \mathrm{KI}$ staining

188 renders the reconstruction of bony material very difficult, an individual of the same species, but

189 not the same specimen, was used to create each skull and mandible. A Bookstein warp

190 (Bookstein, 1989) was then used to fit the bony elements to the reconstructed muscles.

191

\section{Results}

193 The percentage contribution of each muscle to total masticatory muscle mass are given in Table

1941 (absolute masses are given in Table S2) and the percentage split between the masseteric

195 complex, temporalis and pterygoid muscles for each specimen is shown in Fig. 2. Overall, it can

196 be seen that the relative proportion of each jaw-closing muscle is largely consistent between

197 Cryptomys, Fukomys, Georychus, Heliophobius and Heterocephalus, which all have a masseter

198 forming 58-63\%, a temporalis contributing 26-32\%, and pterygoid muscles accounting for 8-

$19911 \%$ of total muscle mass. Bathyergus suillus differs from the other blesmols somewhat, with a

200 relatively larger masseter (69\%) and relatively smaller pterygoids (5\%). The morphology of each

201 muscle is described below and shown in Figs. 3-6.

202

203

\section{Superficial masseter}

204 The superficial masseter is a large muscle in all blesmols, although only a small part of it can be seen in lateral view (Fig. 3). It represents about a quarter of the total masticatory musculature in most of the bathyergid genera. However, Heliophobius has a slightly reduced superficial masseter of about $19 \%$ total muscle mass, and Bathyergus has a greatly increased superficial masseter that occupies over $37 \%$ of the total musculature. This muscle has a tendinous origin via a small attachment site on the skull on the ventral surface of the zygomatic process of the maxilla. The tendon initially runs antero-medial to the deep masseter, but the muscle itself then wraps around the deep masseter to take a more lateral position. The superficial masseter then inserts along the ventral margin of the masseter all the way to the tip of the angular process. The muscle also wraps around the ventral mandibular margin and extends widely over the medial surface of the mandible, forming a pars reflexa (Figs. 4 and 5). This reflected component covers almost the entire medial angular process, leaving just a small area for the insertion of the medial pterygoid muscle. 
Deep masseter

219 The deep masseter is also a large muscle in blesmols, contributing $22-28 \%$ of the total adductor

220

221

222

223

224

225

226

227

228

229

230

231

232

233

234

235

236

237

238

239

240

241

242

243

244

245

246

247

muscle mass in all genera. It originates along the entire length of the ventro-lateral surface of the zygomatic arch, from the attachment site of the superficial masseter anteriorly, to the zygomatic process of the squamosal posteriorly. The insertion of the deep masseter is along the lateral mandibular surface just dorsal to the insertion of the superficial masseter. Thus, in lateral view, the deep masseter covers the posterior half of the mandible (Fig. 3). The separation between the superficial and deep masseter muscles was one of the most difficult aspects of the digital dissection, with these two muscles appearing continuous in some places (Fig. 5). However, the physical dissections of Bathyergus, Cryptomys and Georychus provided confidence that the muscles had been correctly reconstructed. No division of the deep masseter into anterior and posterior sections was identified.

\section{Zygomaticomandibularis}

The zygomaticomandibularis or ZM is a small to medium-sized component of the bathyergid masticatory system. It forms $10-13 \%$ of the total muscle mass in most genera, although this rises to $16 \%$ in Heliophobius and drops to $8 \%$ in Bathyergus. The ZM is divided into three sections infraorbital, anterior and posterior - that were easily identifiable and separable in all specimens (Fig. 6). The anterior ZM originates from the medial surface of the zygomatic arch, with the attachment site spanning the posterior half of the jugal bone and the anterior part of the zygomatic process of the squamosal. The origin of the posterior ZM is immediately posterior to that of the anterior ZM and runs medially along the zygomatic arch until it meets the glenoid fossa. Both muscles insert in a fossa on the lateral surface of the mandible, with the anterior ZM having largely ventrally oriented fibres and the posterior ZM running somewhat anteriorly from origin to insertion. The anterior margin of the anterior $\mathrm{ZM}$ is at the level of the coronoid process of the mandible. Both muscles are covered by the deep masseter in lateral view.

The infraorbital portion of the ZM (IOZM) is usually the largest division of the ZM (although not in Heliophobius where it is smaller than the anterior ZM). It takes a wide origin across the anterior orbital wall and zygomatic process of the maxilla. The fibres then run ventrally and 
248

249

250

251

252

253

254

255

256

257

258

259

260

261

262

263

264

265

266

267

268

269

270

271

272

273

274

275

276

277

converge to a much narrower insertion area on the lower margin of the coronoid process, next to the attachment site of the anterior ZM. In most bathyergid genera, the IOZM origin is confined to the orbit, but in Cryptomys and Fukomys, a very small extension of the IOZM can be seen to push through the infraorbital foramen to take its origin on the rostrum (Figs. 6 and 7).

\section{Temporalis}

The temporalis is large in all bathyergid genera, forming between $26 \%$ and $32 \%$ of the total muscle mass. It originates on the braincase, covering the parietal and the posterior part of the frontal bone (Fig. 3). The posterior limit of the temporalis on the skull is the nuchal crest, the medial border runs along the midsagittal line, and anteriorly it extends into the orbit where it meets the posterior border of the IOZM (Fig. 6). Fibres from all across this wide origin converge on a small insertion on the anterior margin and medial surface of the coronoid process on the mandible. This gives the temporalis a fan-shaped morphology, with fibres from the orbital region running vertically and fibres from the nuchal crest running horizontally over the top of the zygomatic process of the squamosal. A tendon running through the middle of the muscle from the coronoid process upwards appears to divide the ventral part of the muscle into lateral and medial portions, inserting on the lateral and medial surfaces of the coronoid process respectively (Fig. 5). However, these portions come together in the dorsal part of the muscle and it is not possible to subdivide the temporalis here with any certainty. Thus, to avoid introducing errors, the temporalis has been reconstructed as a single component.

\section{Medial pterygoid}

The medial pterygoid comprises between $7 \%$ and $8 \%$ of the total masticatory muscle mass in Cryptomys, Georychus and Heliophobius. It is a little larger in Fukomys, representing almost $10 \%$ total muscle mass, but is notably smaller in Bathyergus occupying only $3 \%$ of the adductor musculature. The medial pterygoid has an elongated anterior portion that extends deeply into the pterygoid fossa where it takes its origin. There is also a smaller part of this muscle that originates on the lateral surface of the pterygoid flange that is ventral to the attachment of the lateral pterygoid muscle. From these attachment sites, the medial pterygoid runs ventro-laterally, fanning out somewhat, to insert on the medial surface of the angular process of the mandible, just 
278 dorsal to the ventral margin. The insertion site is elongate but narrow and bounded on all sides

279 by the superficial masseter (Fig. 4).

280

281

282

283

284

285

286

287

288

289

290

291

292

293

294

295

296

297

298

299

300

301

302

303

304

305

306

307

308

\section{Lateral pterygoid}

The lateral pterygoid is a relatively small muscle forming $2-4 \%$ of the total adductor muscle mass, except in Bathyergus in which it is just under $1 \%$ of the total musculature. It takes its origin from the lateral surface of the pterygoid flange, just dorsal to a part of the medial pterygoid. From there, it runs laterally and posteriorly to an insertion site on the medial surface of the condylar process of the mandible.

\section{Discussion}

The technique of diceCT was successfully used to reveal the masticatory muscle anatomy of all five extant genera of blesmols. Despite being stored in ethanol for a number of years, which can reduce the contrast differences between soft tissues stained with $\mathrm{I}_{2} \mathrm{KI}$ (Gignac et al., 2016), the microCT images produced here were of good quality and allowed the different masticatory muscles to be distinguished from one another (Fig. 5).

The most notable finding from this study is consistency of the relative muscle proportions across the chisel-tooth digging bathyergid genera (Cryptomys, Fukomys, Georychus, Heliophobius). This supports our first hypothesis which predicted that the functional demands of needing to produce a high bite force at wide gape (McIntosh \& Cox, 2016a) would lead to a constrained configuration of masticatory muscles across the family. In these genera, the masseter complex (including superficial and deep masseters, and all parts of the ZM) forms approximately $60 \%$ of adductor muscle mass, the temporalis represents around $30 \%$, and the two pterygoid muscles together make up the final $10 \%$. This distribution of muscle mass, with its dominant masseter, but also relatively large temporalis, has also been reported in a number of rodents, such as the mountain beaver, Aplodontia rufa, several members of the Sciuridae (Ball \& Roth, 1995;

Druzinsky, 2010), and the North American beaver, Castor canadensis (Cox \& Baverstock, 2016). Notably, all of these rodents are sciuromorphous (Wood, 1965), i.e. they have an extension of the deep masseter on to the rostrum, and they are all relatively distantly related to blesmols (Fabre et al., 2012). In contrast, more closely related rodents, from the suprafamilial 
309 clade Ctenohystrica to which blesmols belong, generally differ from the bathyergid pattern by

310 having an even more dominant masseter ( $70 \%$ or more of total muscle mass) and a much reduced

311 temporalis (15\% or lower), e.g. Hydrochoerus (Muller, 1933), Hystrix (Turnbull, 1970) and

312 Ctenomys (Becerra, Casinos \& Vassallo, 2013). These rodents are hystricomorphous and have a

313 substantial extension of the IOZM through the infraorbital foramen on to the rostrum. It is

314 notable that the rodent species that more closely resemble bathyergids in the proportions of their

315 jaw-closing muscles are those that require high bite forces at the incisors, either for processing

316 mechanically demanding food items (Smith \& Follmer, 1972) or for tree-felling (Rosell et al.,

317 2005). It appears that the demands of chisel-tooth digging may have driven convergent evolution

318 of a similar distribution of muscle mass in blesmols.

320 The second hypothesis of this study predicted that the chisel-tooth digging bathyergids would

321 resemble Heterocephalus glaber in their masticatory muscle anatomy. This hypothesis is also

322 supported, with the relative proportions of each muscle in the naked mole-rat (Cox \& Faulkes,

323 2014) being very similar to that seen in Cryptomys, Fukomys, Georychus and Heliophobius.

324 Given this similarity, it is possible that this muscle arrangement is ancestral for the

325 Bathyergoidea (the superfamily containing Heterocephalidae and Bathyergidae). However, given

326 the strong pressures exerted on morphology by chisel-tooth digging (Lessa, 1990; Samuels \&

327 Van Valkenburgh, 2009; Gomes Rodrigues, Šumbera \& Hautier, 2016; McIntosh \& Cox,

328 2016a,b), it is also possible that this configuration of adductor muscles evolved independently in

329 the two families, especially given that they appear to have diverged over 30 million years ago

330 (Patterson \& Upham, 2014).

331

332 The exception to the common arrangement of masticatory muscles in the Bathyergidae is

333 Bathyergus, the only genus of scratch-digging blesmols. The distribution of muscles in this

334 genus is $69 \%$ masseter, $26 \%$ temporalis and 5\% pterygoids. Thus, our third hypothesis that

335 Bathyergus would differ from the chisel-tooth diggers is supported. However, it should be noted

336 that only one specimen of each genus was available for study, so no statistical test of the

337 difference between scratch and chisel-tooth diggers could be undertaken. We further predicted

338 that the temporalis would be relatively smaller in the scratch digger, owing to the perceived

339 importance of the temporalis in chisel-tooth digging (Samuels \& Van Valkenburgh, 2009; 
340 McIntosh \& Cox, 2016a), but this was not the case. The temporalis muscle in Bathyergus forms

341 a similar proportion of total adductor muscle mass as in Heliophobius and Fukomys; instead the

342 masseter complex in Bathyergus, in particular the superficial masseter, is relatively larger, and

343 the pterygoid muscles form a smaller part of the masticatory musculature. The lack of difference

344 in the relative temporalis mass may reflect the fact that all bathyergid genera, Bathyergus

345 included, have diets that incorporate hard foods such as the roots and tubers of geophytes, many

346 of which are of large size and would require the use of a wide gape. Thus the size of the

347 temporalis may be driven more by diet than by mode of digging.

348

349

350

The function of the superficial masseter has been debated by a number of authors, but it is generally thought to be important in the power stroke of both gnawing and chewing (Gorniak, 1977; Byrd, 1981) as well as being the main protractor of the lower jaw (Hiiemae, 1971), based on the antero-posterior orientation of the muscle fibres. Thus, the enlarged superficial masseter in Bathyergus may be an adaptation to its diet which incorporates many tough grasses and bulbs (Bennett \& Faulkes, 2000). The function of the expansion of the superficial masseter on the medial mandibular surface, the pars reflexa, is less clear. Satoh \& Iwaku (2004) have suggested that it may enable a wider gape by increasing the resting length of the muscle fibres. In most bathyergid genera, this would be advantageous as it would facilitate the wide opening of the jaws necessary for chisel-tooth digging. Blesmols of the genus Bathyergus do not dig with their teeth (Stein, 2000) but the males do fight with their incisors (Bennett \& Faulkes, 2000), again requiring a wider gape. Whether or not the fighting behaviour requires a wider gape (and thus larger superficial masseter) than chisel-tooth digging is at present unclear.

The reduced pterygoid muscles in Bathyergus, particularly the medial pterygoid, may also be a reflection of scratch digging behaviour. It has previously been noted that the medial pterygoid contracts more strongly during incisor gnawing than molar chewing (Weijs \& Dantuma, 1975). Thus, scratch digging mole-rats may not need such large pterygoid muscles as their chisel-tooth digging counterparts. Alternatively, the reduced medial pterygoid may simply reflect the reduced area for attachment on the medial surface of the angular process, resulting from the increased size of the pars reflexa of the superficial masseter in Bathyergus (Satoh \& Iwaku, 2004). 
371 In general, the muscle reconstructions presented here are in agreement with the previous

372 descriptions of bathyergid jaw musculature given by Tullberg (1899) and Morlok (1983), but

373 differ in some respects from the anatomy reported by Boller (1970) and Van Daele, Herrel \&

374 Adriaens (2009). The main difference arises in the morphology of the superficial masseter,

375 which in Boller (1970) and Van Daele, Herrel \& Adriaens (2009) is reported to have a wide

376 expansion across the deep masseter in lateral view and is split into sections known as M1a, M1b

377 and M2. Here, we agree with Morlok (1983) that the main part of the superficial masseter in

378 lateral view is very slender and runs along the ventral margin of the mandible, and that most of

379 the muscle attaching to the lateral surface of the mandible is the deep masseter. It is clear that the

380 division between the superficial and deep masseter muscles is quite difficult to determine in

381 some places, but following both digital and physical dissection, we are confident that the

382 morphology presented here is correct, and moreover resembles that reported for the naked mole-

383 rat (Cox \& Faulkes, 2014).

384

385 The other major difference between the reconstructions here and that of Boller (1970) is with

386 regard to the temporalis. The illustrations of Cryptomys in Boller (1970) show the temporalis

387 extending ventrally on to the mandible, between two sections of the ZM muscle. We believe this

388 'pars zygomatica of the temporalis' to be a misidentification of the anterior ZM resulting from

389 the close apposition of the two muscles, and the insertion of the temporalis on the mandible to be

390 restricted to the coronoid process.

391

392 The virtual reconstructions presented here highlight one well-known peculiarity of bathyergid

393 musculature - the lack of jaw-closing muscles attaching to the rostrum in this family. Species in

394 the Ctenohystrica, which includes the blesmols, are almost all hystricomorphous; that is, they

395 have a greatly enlarged infraorbital foramen, through which a portion of the ZM muscle (the

396 IOZM) extends to take its origin on the rostrum (Hautier, Cox \& Lebrun, 2015). In the

397 Bathyergidae, the infraorbital foramen is much smaller and very little, if any, muscle passes

398 through it. This is very similar to the condition known as protrogomorphy, which is believed to

399 be the ancestral state for rodents (Wood, 1965). Here we have designated the rostral most section

400 of the ZM as the 'IOZM', but only in Cryptomys and Fukomys does it pass through the

401 infraorbital foramen. In the remaining three genera, the IOZM is confined to the orbit. Maier \& 
402 Schrenk (1987) noted that some muscle fibres pass through the infraorbital foramen in

403 Bathyergus and Georychus in early ontogeny, but subsequently retreat and are absent from the 404 rostrum at birth. Similarly, no part of the IOZM was found on the rostrum in the specimens of 405 these two genera in this study.

406

407

Despite not extending on to the rostrum, the IOZM is usually the largest part of the ZM in 408 bathyergids and has a wide origin across the anterior part of the orbit. Indeed, in all the specimens studied here, its posterior margin meets the anterior margin of the temporalis in the orbit. Such an arrangement of muscles has likely been made possible by the extreme reduction of the eye in these fossorial species, which has left space into which the muscles have expanded (Fig. 7). The large IOZM also gives a clue to the evolutionary history of the masticatory muscles in Bathyergidae. Although frequently referred to as being 'protrogomorphous' (Tullberg, 1899; Wood, 1965, 1985), the morphology of the bathyergid ZM muscle does not resemble that of the extant protrogomorph, Aplodontia rufa, in which the ZM origin is restricted to the zygomatic arch and does not extend dorsally into the orbit. Instead, the bathyergid IOZM more closely resembles that of other hystricomorphs, minus the extension on to the rostrum, a morphology that seems more likely to be secondarily derived than ancestrally retained. This hypothesis is also supported by the phylogenetic position of bathyergids within the otherwise hystricomorph clade Ctenohystrica (Swanson et al., 2019), the presence of hystricomorphy in some fossil bathyergids (Lavocat, 1973), and the previously mentioned presence of hystricomorphy in early development of some blesmols (Maier \& Schrenk, 1987).

The loss of the rostral extension of the IOZM seems an unusual morphological change, given that this muscle is known to improve the efficiency of molar chewing in rodents (Cox et al., 2012; Cox, 2017). It is possible that it is an adaptation towards increased use of the incisors in digging, as has been suggested for Heterocephalus glaber (Cox \& Faulkes, 2014). Shortening the rostrum would decrease the out-lever of incisor biting and would thus increase bite force, but would leave less room for rostral muscle attachment. In addition, the loss of the IOZM from the rostrum could be a strategy for increasing maximum gape, which is also important in chisel-tooth digging (McIntosh \& Cox, 2016a). It should be noted that Bathyergus also lacks the rostral 
433 and that having lost the rostral IOZM once in its evolutionary history, Bathyergus has not re434 evolved it.

435

436

437

\section{Conclusion}

438

439

440

441

442

443

444

445

446

447

448

449

450

451

452

453

454

455

456

457

458

459

460

461

The masticatory musculature of the Bathyergidae is dominated by the masseter muscle, but also has a relatively large temporalis, similar to the condition seen in many sciuromorph rodents. The ZM muscle does not extend on to the rostrum (except very slightly in Cryptomys and Fukomys), a condition that is thought to be secondarily derived from a hystricomorph ancestor. The relative proportions of the jaw-closing muscles are largely consistent between the chisel-tooth digging blesmols, but the scratch digging genus, Bathyergus, differs in having a larger superficial masseter and smaller pterygoid muscles. Despite the deep split between the Heterocephalidae and the Bathyergidae, the jaw adductor musculature of the naked mole-rat is very similar to that of the chisel-tooth digging bathyergids.

\section{Acknowledgements}

The authors thank Keturah Smithson (Cambridge Biotomography Centre, University of Cambridge) for microCT scanning the specimens.

\section{References}

Ball SS, Roth VL. 1995. Jaw muscles of new-world squirrels. Journal of Morphology 224: 265 291.

Becerra F, Casinos A, Vassallo AI. 2013. Biting performance and skull biomechanics of a chisel tooth digging rodent (Ctenomys tuconax; Caviomorpha; Octodontoidea). Journal of Experimental Zoology Part A: Ecological Genetics and Physiology 319A: 74-85.

Bennett NC, Faulkes CG. 2000. African Mole-rats: Ecology and Eusociality. Cambridge: Cambridge University Press.

Blanga-Kanfi S, Miranda H, Penn O, Pupko T, DeBry RW, Huchon D. 2009. Rodent phylogeny revised: analysis of six nuclear genes from all major rodent clades. $B M C$ Evolutionary Biology 9: 71. 
462 Boller N. 1970. Untersuchungen an Schädel, Kaumuskulatur und äußerer Hirnform von

463

464

465

466

467

468

469

470

471

472

473

474

475

476

477

478

479

480

481

482

483

484

485

486

487

490

491

Cryptomys hottentotus (Rodentia, Bathyergidae). Zeitschrift für wissenschaftlische Zoologie 181: 7-65.

Bookstein FL. 1989. Principal warps: thin-plate splines and the decomposition of deformations. IEEE Transactions on Pattern Analysis and Machine Intelligence 11: 567-585.

Brandt JF. 1855. Beiträge zur nähern Kenntniss der Säugethiere Russlands. Mémoires de l'Academie Imperiale des Sciences de St Pétersbourg, Sixième Série 9 : 1-375.

Burgin CJ, Colella JP, Kahn PL, Upham NS. 2018. How many species of mammals are there? Journal of Mammalogy 99: 1-14.

Byrd KE. 1981. Mandibular movement and muscle activity during mastication in the guinea pig (Cavia porcellus). Journal of Morphology 170: 147-169.

Cox PG. 2017. The jaw is a second-class lever in Pedetes capensis (Rodentia: Pedetidae). PeerJ 5: e3741.

Cox PG, Baverstock H. 2016. Masticatory muscle anatomy and feeding efficiency of the American beaver, Castor canadensis (Rodentia, Castoridae). Journal of Mammalian Evolution 23: 191-200.

Cox PG, Faulkes CG. 2014. Digital dissection of the masticatory muscles of the naked mole-rat, Heterocephalus glaber (Mammalia, Rodentia). PeerJ 2: e448.

Cox PG, Jeffery N. 2011. Reviewing the morphology of the jaw-closing musculature in squirrels, rats, and guinea pigs with contrast-enhanced microCT. Anatomical Record 294: 915-928.

Cox PG, Jeffery N. 2015. The muscles of mastication in rodents and the function of the medial pterygoid. In: Cox PG, Hautier L, eds. Evolution of the rodents: advances in phylogeny, functional morphology and development. Cambridge: Cambridge University Press, 350372.

Cox PG, Rayfield EJ, Fagan MJ, Herrel A, Pataky TC, Jeffery N. 2012. Functional evolution of the feeding system in rodents. PLoS ONE 7: e36299.

Davies KTJ, Bennett NC, Tsagkogeorga G, Rossiter SJ, Faulkes CG. 2015. Family wide molecular adaptations to underground life in African mole-rats revealed by phylogenomic analysis. Molecular Biology and Evolution 32: 3089-3107. 
492

493

494

495

496

497

498

499

500

501

502

503

504

505

506

507

508

509

510

511

512

513

514

515

516

517

518

519

520

521

522

Druzinsky RE. 2010. Functional anatomy of incisal biting in Aplodontia rufa and sciuromorph rodents - Part 1: Masticatory muscles, skull shape and digging. Cells Tissues Organs 191: 510-522.

Fabre P-H, Hautier L, Dimitrov D, Douzery EJP. 2012. A glimpse on the pattern of rodent diversification: a phylogenetic approach. BMC Evolutionary Biology 12: 88.

Faulkes, CG, Bennett NC, Cotterill FPD, Stanley W, Mgode GF, Verheyen E. 2011. Phylogeography and cryptic diversity of the solitary-dwelling silvery mole-rat, genus Heliophobius (family: Bathyergidae). Journal of Zoology 285: 324-338.

Faulkes CG, Bennett NC. 2013. Plasticity and constraints on social evolution in African molerats: ultimate and proximate factors. Philosophical Transactions of the Royal Society B: Biological Sciences 368: 20120347.

Faulkes CG, Mgode GF, Archer EK, Bennett NC. 2017. Relic populations of Fukomys molerats in Tanzania: description of two new species $F$. livingstoni sp. nov. and $F$. hanangensis sp. nov. PeerJ 5: e3214.

Faulkes CG, Verheyen E, Verheyen W, Jarvis JUM, Bennett NC. 2004. Phylogeographical patterns of genetic divergence and speciation in African mole- rats (Family: Bathyergidae). Molecular Ecology 13: 613-629.

Gignac PM, Kley NJ. 2014. Iodine-enhanced microCT imaging: Methodological refinements for the study of soft-tissue anatomy of post-embryonic vertebrates. Journal of Experimental Zoology Part B: Molecular and Developmental Evolution 322B: 166-176.

Gignac PM, Kley NJ, Clarke JA, Colbert MW, Morhardt AC, Cerio D, Cost IN, Cox PG, Daza JD, Early CM, Echols MS, Henkelman RM, Herdina AN, Holliday CM, Li Z, Mahlow K, Merchant S, Müller J, Orsborn C, Paluh DJ, Thies ML, Tsai HP, Witmer LM. 2016. Diffusible iodine-based contrast-enhanced computed tomography (diceCT): an emerging tool for rapid, high-resolution, 3-D imaging of metazoan soft tissues. Journal of Anatomy 228: 889-909.

Gomes Rodrigues H, Šumbera R, Hautier L. 2016. Life in burrows channelled the morphological evolution of the skull in rodents: the case of African mole-rats (Bathyergidae, Rodentia). J Mamm Evol 23: 175-189.

Gorniak GC. 1977. Feeding in golden hamsters, Mesocricetus auratus. Journal of Morphology 154: 427-458. 
523 Hautier L, Cox PG, Lebrun R. 2015. Grades and clades among rodents: the promise of

524

525

526

527

528

529

530

531

532

533

534

535

536

537

538

539

540

541

542

543

544

545

546

547

548

549

550

551

552

553 geometric morphometrics. In: Cox PG, Hautier L, eds. Evolution of the rodents: advances in phylogeny, functional morphology and development. Cambridge: Cambridge University Press, 277-299.

Hiiemae K. 1971. The structure and function of the jaw muscles in the rat (Rattus norvegicus L.) III. The mechanics of the muscles. Zoological Journal of the Linnean Society 50: 111132.

Ingram CM, Burda H, Honeycutt RL. 2004. Molecular phylogenetics and taxonomy of the African mole- rats, genus Cryptomys and the new genus Coetomys Gray, 1864. Molecular Phylogenetics and Evolution 31: 997-1014.

Jeffery NS, Stephenson R, Gallagher JA, Jarvis JC, Cox PG. 2011. Micro-computed tomography with iodine staining reveals the arrangement of muscle fibres. Journal of Biomechanics 44: 189-192.

Kock D, Ingram CM, Frabotta LJ, Honeycutt RL, Burda H. 2006. On the nomenclature of Bathyergidae and Fukomys n. gen. (Mammalia: Rodentia). Zootaxa 1142: 51-55.

Landry SO. 1957. The interrelationships of the New and Old World Rodents. University of California Publications in Zoology 56: 1-118.

Lavocat R. 1973. Les rongeurs du Miocène de l'Afrique Orientale. I. Miocène Inférieur. Mémoires et Travaux de l'Institut de l'Ecole Pratique des Hautes Etudes, Montpellier 1: $1-284$.

Lessa EP. 1990. Morphological evolution of subterranean mammals: integrating structural, functional, and ecological perspectives. In: Nevo E, Reig OA, eds. Evolution of Subterranean Mammals at the Organismal and Molecular Levels. New York: WileyLiss, 211-230.

Maier W, Schrenk F. 1987. The hystricomorphy of the Bathyergidae, as determined from ontogenetic evidence. Zeitschrift für Säugetierkunde 52: 156-164.

McIntosh AF, Cox PG. 2016a. Functional implications of craniomandibular morphology in African mole-rats (Rodentia: Bathyergidae). Biological Journal of the Linnean Society 117: 447-462.

McIntosh AF, Cox PG. 2016b. The impact of digging on craniodental morphology and integration. Journal of Evolutionary Biology 29: 2383-2394. 
554 Mein P, Pickford M. 2008. Early Miocene Rodentia from the Northern Sperrgebiet, Namibia.

555

556

557

558

559

560

561

562

563

564

565

566

567

568

569

570

571

572

573

574

575

576

577

578

579

580

581

582

583 Memoir of the Geological Survey of Namibia 20: 235-290.

Metscher BD. 2009. MicroCT for comparative morphology: simple staining methods allow high-contrast 3D imaging of diverse non-mineralized animal tissues. BMC Physiology 9: 11.

Morlok WF. 1983. Vergleichend- und funktionell-anatomische Untersuchungen an Kopf, Hals und Vorderextremität subterraner Nagetiere (Mammalia, Rodentia). Courier Forschungsinstitut Senckenberg 64: 1-237.

Müller A. 1933. Die Kaumuskulatur des Hydrochoerus capybara und ihre Bedeutung für die Formgestaltung des Schädels. Morphologisches Jahrbuch 72: 1-59.

Murphy RA, Beardsley AC. 1974. Mechanical properties of the cat soleus muscle in situ. American Journal of Physiology 227: 1008-1013.

Patterson BD, Upham NS. 2014. A newly recognized family from the Horn of Africa, the Heterocephalidae (Rodentia: Ctenohystrica). Zoological Journal of the Linnean Society 172: $942-963$.

Rosell F, Bozsér O, Collen P, Parker H. 2005. Ecological impact of beavers Castor fiber and Castor canadensis and their ability to modify ecosystems. Mammal Review 35: 248-276.

Samuels JX, Van Valkenburgh B. 2009. Craniodental adaptations for digging in extinct burrowing beavers. Journal of Vertebrate Paleontology 29: 254-268.

Satoh K, Iwaku F. 2004. Internal architecture, origin-insertion site, and mass of jaw muscles in Old World hamsters. Journal of Morphology 267: 987-999.

Smith CC, Follmer D. 1972. Food preferences of squirrels. Ecology 53: 82-91.

Stein BR. 2000. Morphology of subterranean rodents. In: Lacey EA, Patton JL, Cameron GN, eds. Life Underground: The Biology of Subterranean Rodents. Chicago: University of Chicago Press, 19-61.

Swanson MT, Oliveros CH, Esselstyn JA. 2019. A phylogenomic rodent tree reveals the repeated evolution of masseter architectures. Proceedings of the Royal Society B 286: 20190672.

Thorington RW, Darrow K. 1996. Jaw muscles of Old World squirrels. Journal of Morphology 230: $145-165$. 
584 Tullberg T. 1899. Über das System der Nagethiere: eine phylogenetische Studie. Nova Acta Regiae Societatis Scientarium Upsaliensis Series 3 18: 1-514.

Turnbull WD. 1970. Mammalian masticatory apparatus. Fieldiana (Geology) 18: 147-356.

Van Daele PAAG, Verheyen E, Brunain M, Adriaens D. 2007. Cytochrome $b$ sequence analysis reveals differential molecular evolution in African mole-rats of the chromosomally hyperdiverse genus Fukomys (Bathyergidae, Rodentia) from the Zambezian region. Molecular Phylogenetics and Evolution 45: 142-157.

Van Daele PAAG, Herrel A, Adriaens D. 2009. Biting performance in teeth-digging African mole-rats (Fukomys, Bathyergidae, Rodentia). Physiological and Biochemical Zoology 82: $40-50$.

Vickerton P, Jarvis J, Jeffery N. 2013. Concentration-dependent specimen shrinkage in iodineenhanced microCT. Journal of Anatomy 223: 185-193.

Visser JH, Bennett NC, Jansen van Vuuren B. 2019. Phylogeny and biogeography of the African Bathyergidae: a review of patterns and processes. PeerJ 7: e7730.

Weijs WA, Dantuma R. 1975. Electromyography and mechanics of mastication in the albino rat. Journal of Morphology 146: 1-34.

Wilson DE, Lacher TE, Mittermeier RA. 2016. Handbook of the Mammals of the World. Vol. 6. Lagomorphs and Rodents I. Barcelona: Lynx Edicions.

Wood AE. 1965. Grades and clades among rodents. Evolution 19: 115-130.

Wood AE. 1985. The relationships, origin and dispersal of the hystricognathous rodents. In: Luckett WP, Hartenberger JL, eds. Evolutionary Relationships among Rodents: a Multidisciplinary Analysis. New York: Plenum Press, 475-513.

Woods CA. 1972. Comparative myology of jaw, hyoid, and pectoral appendicular regions of New and Old World hystricomorph rodents. Bulletin of the American Museum of Natural History 147: 115-198.

Woods CA, Hermanson JW. 1985. Myology of hystricognath rodents: an analysis of form, function and phylogeny. In: Luckett WP, Hartenberger JL, eds. Evolutionary Relationships among Rodents: a Multidisciplinary Analysis. New York: Plenum Press, 685-712.

Woods CA, Howland EB. 1979. Adaptive radiation of capromyid rodents: anatomy of the masticatory apparatus. Journal of Mammalogy 60: 95-116. 
Figure legends

626

Figure 1. Genus-level phylogeny of the African mole-rats. Tree based on mitochondrial 12S rRNA and cytochrome b sequence data, and analysis of 3,999 nuclear genes (Faulkes et al., 2004; Ingram, Burda \& Honeycutt, 2004; Davies et al., 2015). A chronologically calibrated scale in millions of years ago is illustrated beneath the tree, estimated using a molecular clock approach, and using the bathyergid fossil Proheliophobius for calibration of genetic distances. Adapted from Faulkes and Bennett (2013).

Figure 2. Relative contributions of the masseter, temporalis and pterygoid muscles to total adductor muscle mass in each genus of Bathyergidae and Heterocephalidae. Data for Heterocephalus from Cox \& Faulkes (2014).

Figure 3. Masticatory muscles of Bathyergidae. Left lateral view of a 3D reconstruction of the cranium, mandible and masticatory muscles of: A, Bathyergus suillus; B, Georychus capensis; C, Cryptomys hottentotus; D, Fukomys mechowi; E, Heliophobius argenteocinereus. Abbreviations: azm, anterior zygomaticomandibularis; dm, deep masseter; iozm, infraorbital portion of the zygomaticomandibularis; sm, superficial masseter; $\mathrm{t}$, temporalis. Scale bar $=5 \mathrm{~mm}$.

Figure 4. Superficial master and pterygoid muscles of Cryptomys hottentotus. Left lateral view of a $3 \mathrm{D}$ reconstruction of the cranium, mandible, superficial masseter and pterygoid muscles. Cranium and mandible transparent for visualisation of muscles attaching to medial mandibular surface. Abbreviations: lp, lateral pterygoid; mp, medial pterygoid; pr, pars reflexa of the superficial masseter; sm, superficial masseter. Scale bar $=5 \mathrm{~mm}$. 
646 Figure 5. Coronal diceCT slice of Bathyergus suillus. MicroCT slice through the head of

647

648

649

650

651

652

653

654

655

656

657

658

659

660

661

662

663
Bathyergus suillus stained with iodine potassium iodide. Abbreviations: azm, anterior zygomaticomandibularis (dark green); dm, deep masseter (dark blue); man, mandible; pr, pars reflexa of the superficial masseter (light blue); pzm, posterior zygomaticomandibularis (light green); sm, superficial masseter (light blue); t, temporalis (red); ten, tendon of temporalis. White line on 3D reconstruction shows position of slice. Scale bar $=5 \mathrm{~mm}$.

Figure 6. Temporalis and zygomaticomandibularis muscles of Bathyergidae. Left lateral view of a $3 \mathrm{D}$ reconstruction of the cranium, mandible, temporalis and zygomaticomandibularis of: A, Bathyergus suillus; B, Georychus capensis; C, Cryptomys hottentotus; D, Fukomys mechowi; E, Heliophobius argenteocinereus. Abbreviations: azm, anterior zygomaticomandibularis; iozm, infraorbital portion of the zygomaticomandibularis; pzm, posterior zygomaticomandibularis; $\mathrm{t}$, temporalis. Scale bar $=5 \mathrm{~mm}$.

Figure 7. Transverse diceCT slice of Cryptomys hottentotus. MicroCT slice through the head of Cryptomys hottentotus stained with iodine potassium iodide. Abbreviations: iozm, infraorbital portion of zygomaticomandibularis (dark green); on, optic nerve; $t$, temporalis (red). White line on 3D reconstruction shows position of slice. Scale bar $=5$ $\mathrm{mm}$. 


\section{Table 1 (on next page)}

Percentage of total masticatory muscle adductor mass occupied by each jaw-closing muscle in each mole-rat genus.

Values for Heterocephalus glaber from Cox \& Faulkes (2014). Absolute muscle masses given in Table S2. 
1 Tables

2 Table 1. Percentage of total masticatory muscle adductor mass occupied by each jaw-closing muscle in each mole-rat genus.

4

\begin{tabular}{|c|c|c|c|c|c|c|}
\hline & Bathyergus & Cryptomys & Fukomys & Georychus & Heliophobius & Heterocephalus \\
\hline $\begin{array}{l}\text { Superficial } \\
\text { masseter }\end{array}$ & 37.5 & 24.5 & 27.4 & 25.9 & 19.3 & 23.4 \\
\hline Deep masseter & 23.7 & 23.8 & 22.1 & 22.8 & 27.7 & 25.5 \\
\hline Anterior ZM & 2.7 & 1.8 & 2.2 & 2.7 & 5.3 & 2.9 \\
\hline Posterior ZM & 1.8 & 2.9 & 4.2 & 3.6 & 6.0 & 2.6 \\
\hline IOZM & 3.7 & 5.6 & 4.9 & 7.0 & 4.8 & 5.4 \\
\hline Temporalis & 26.0 & 31.8 & 26.2 & 28.0 & 26.1 & 32.2 \\
\hline $\begin{array}{l}\text { Medial } \\
\text { pterygoid }\end{array}$ & 3.7 & 7.7 & 9.7 & 7.8 & 7.2 & 6.1 \\
\hline $\begin{array}{l}\text { Lateral } \\
\text { pterygoid }\end{array}$ & 0.9 & 2.0 & 3.2 & 2.3 & 3.7 & 2.0 \\
\hline
\end{tabular}

5

6 Values for Heterocephalus glaber from Cox \& Faulkes (2014). Absolute muscle masses given in Table S2.

8 


\section{Figure 1}

Genus-level phylogeny of the African mole-rats.

Tree based on mitochondrial $12 \mathrm{~S}$ rRNA and cytochrome $b$ sequence data, and analysis of 3,999 nuclear genes (Faulkeset al., 2004; Ingram, Burda \& Honeycutt, 2004; Davieset

al.,2015). A chronologically calibrated scale inmillions of years ago is illustrated beneath the tree,estimated using a molecular clock approach, and using the bathyergid fossilProheliophobiusfor calibration of genetic distances.Adapted from Faulkes and Bennett (2013). 


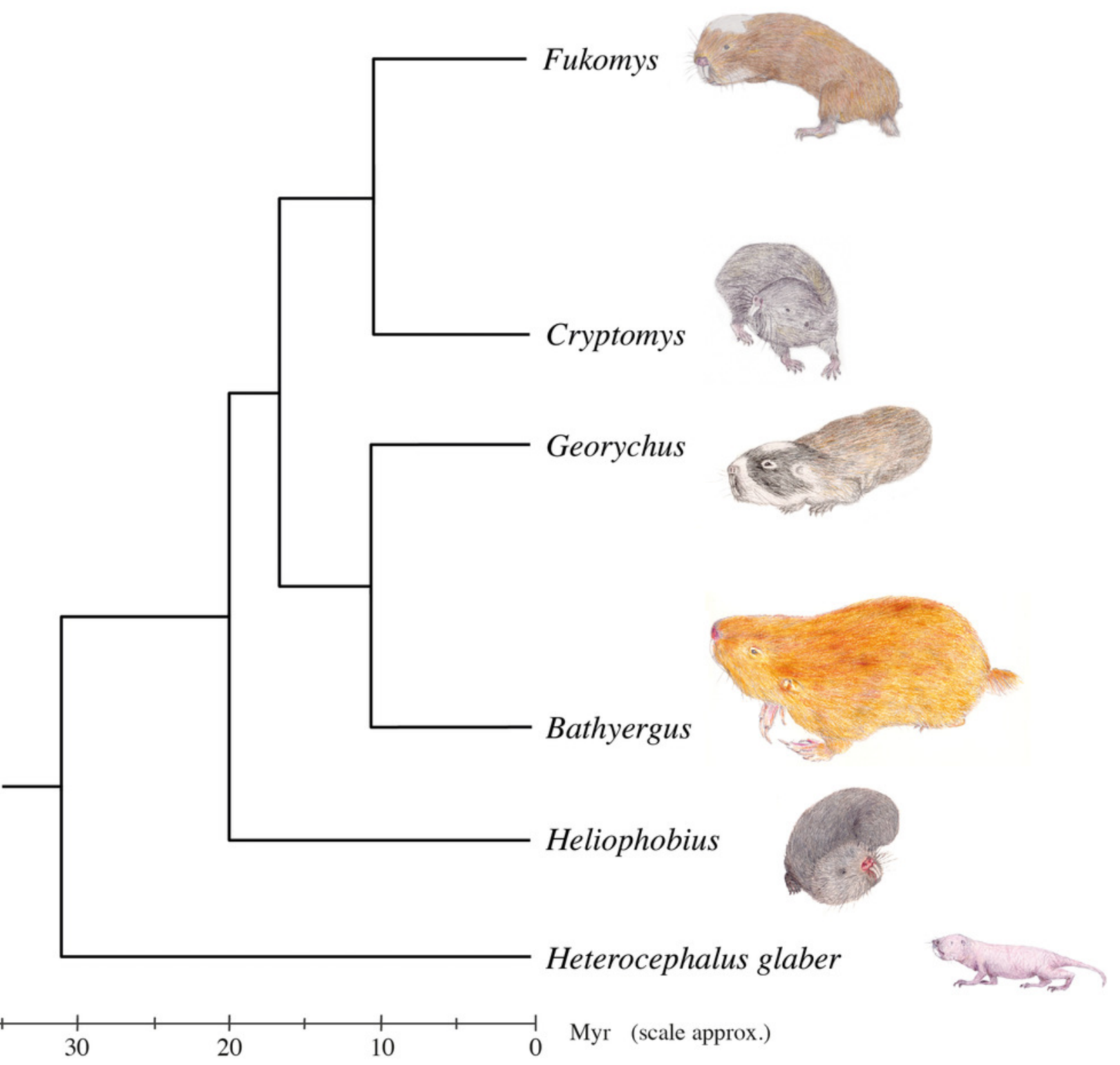




\section{Figure 2}

Relative contributions of the masseter, temporalis and pterygoid muscles to total adductor muscle mass in each genus of Bathyergidae and Heterocephalidae.

Data for Heterocephalus from Cox \& Faulkes (2014).

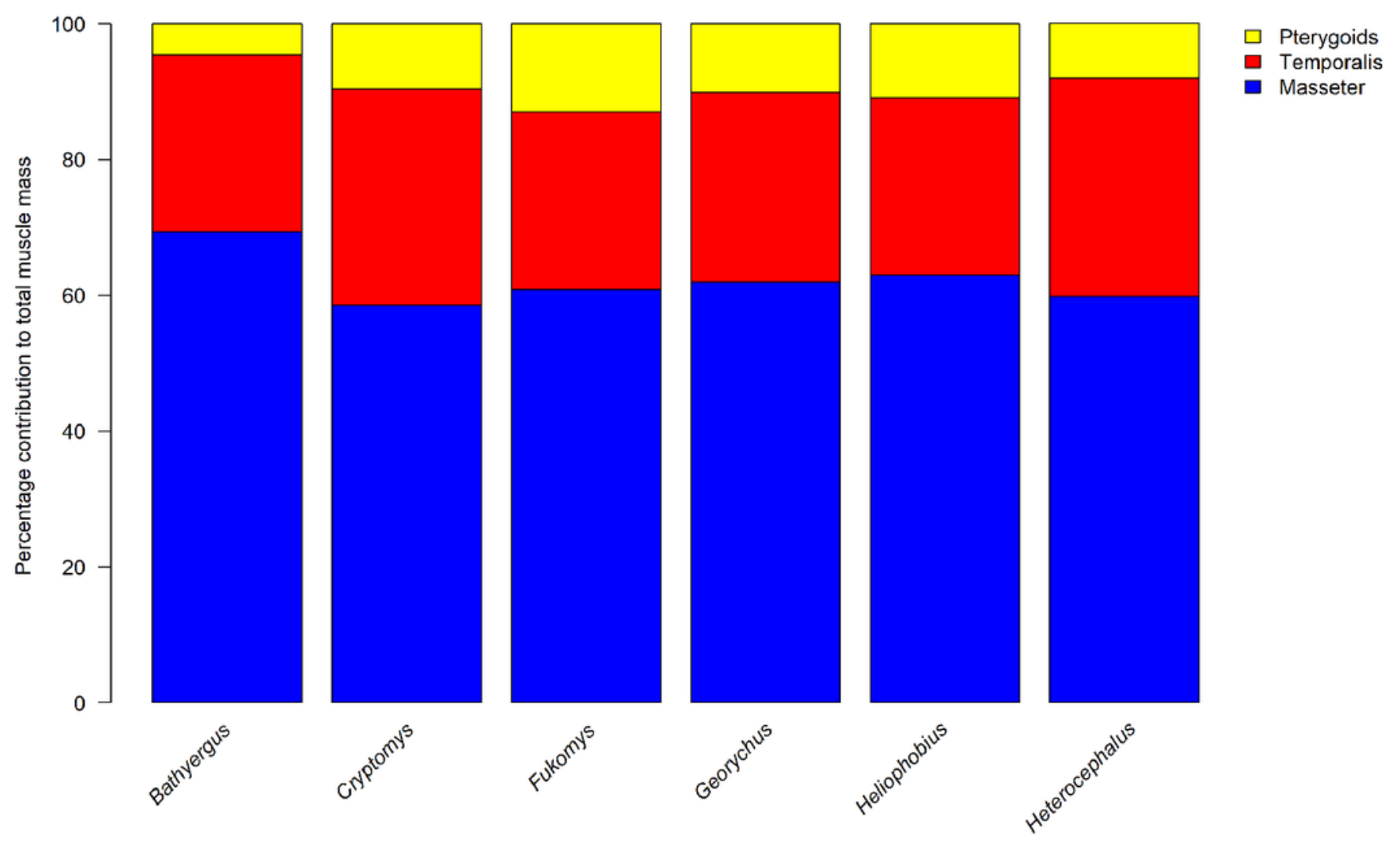


Figure 3

Masticatory muscles of Bathyergidae.

Left lateral view of a 3D reconstruction of the cranium, mandible and masticatory muscles of:

A, Bathyergus suillus; B, Georychus capensis; C, Cryptomys hottentotus; D, Fukomys

mechowi; E, Heliophobius argenteocinereus. Abbreviations: azm, anterior

zygomaticomandibularis; $\mathrm{dm}$, deep masseter; iozm, infraorbital portion of the

zygomaticomandibularis; sm, superficial masseter; t, temporalis. Scale bar $=5 \mathrm{~mm}$. 

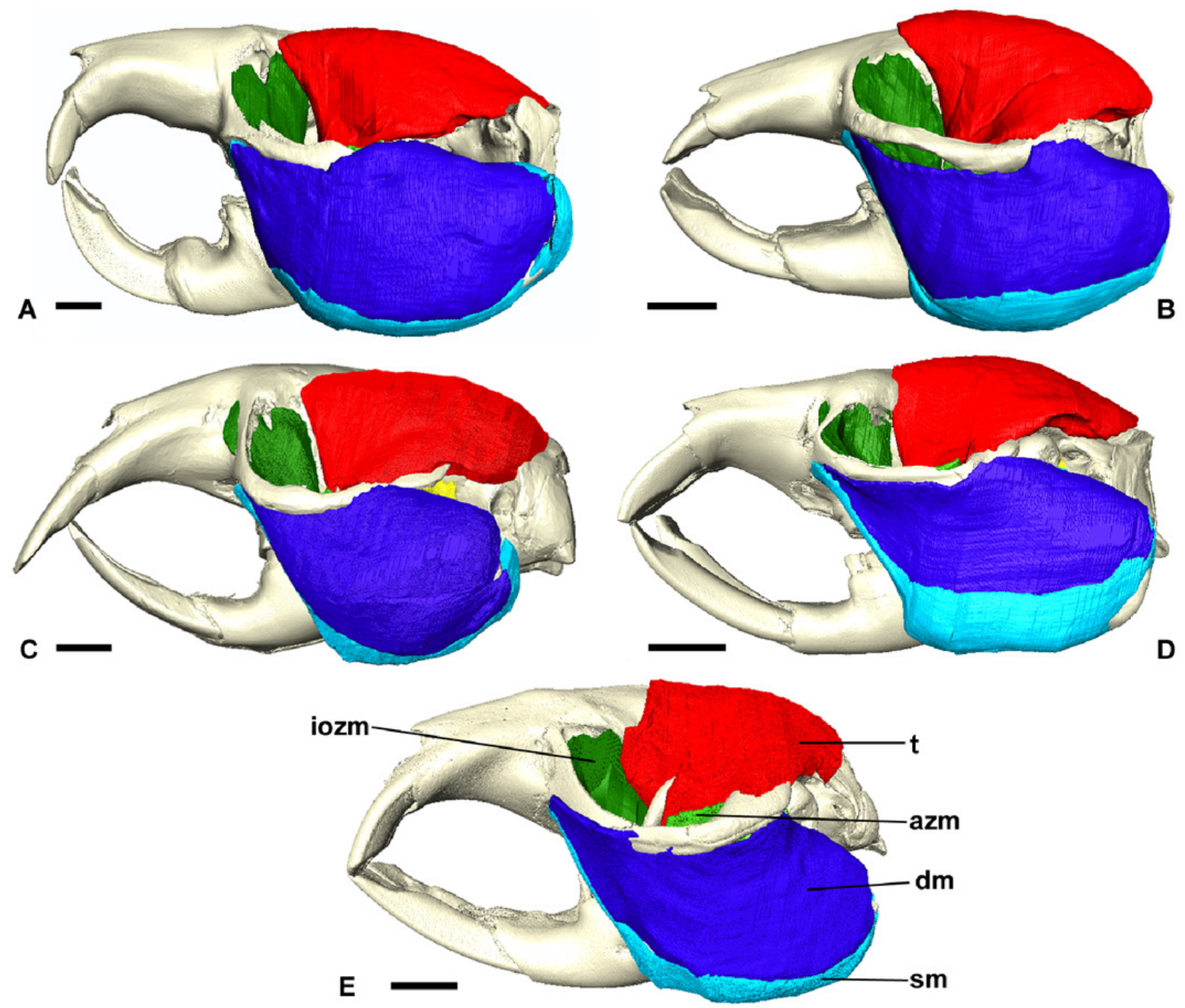
Figure 4

Superficial master and pterygoid muscles of Cryptomys hottentotus.

Left lateral view of a 3D reconstruction of the cranium, mandible, superficial masseter and pterygoid muscles. Cranium and mandible transparent for visualisation of muscles attaching to medial mandibular surface. Abbreviations: Ip, lateral pterygoid; mp, medial pterygoid; pr, pars reflexa of the superficial masseter; sm, superficial masseter. Scale bar $=5 \mathrm{~mm}$.

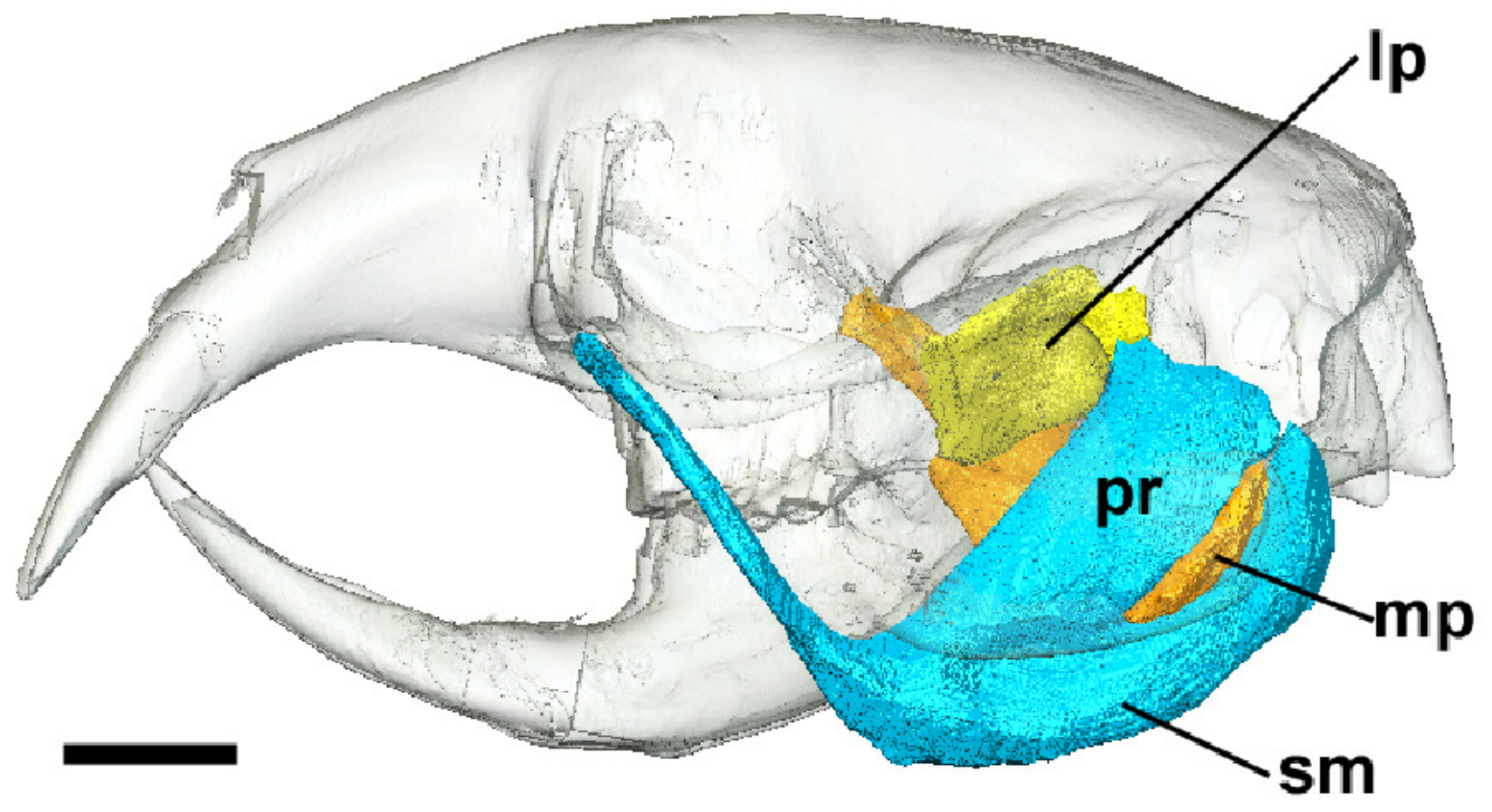




\section{Figure 5}

Coronal diceCT slice of Bathyergus suillus.

MicroCT slice through the head of Bathyergus suillus stained with iodine potassium iodide. Abbreviations: azm, anterior zygomaticomandibularis (dark green); dm, deep masseter (dark blue); man, mandible; pr, pars reflexa of the superficial masseter (light blue); pzm, posterior zygomaticomandibularis (light green); sm, superficial masseter (light blue); t, temporalis (red); ten, tendon of temporalis. White line on 3D reconstruction shows position of slice. Scale bar $=5 \mathrm{~mm}$. 


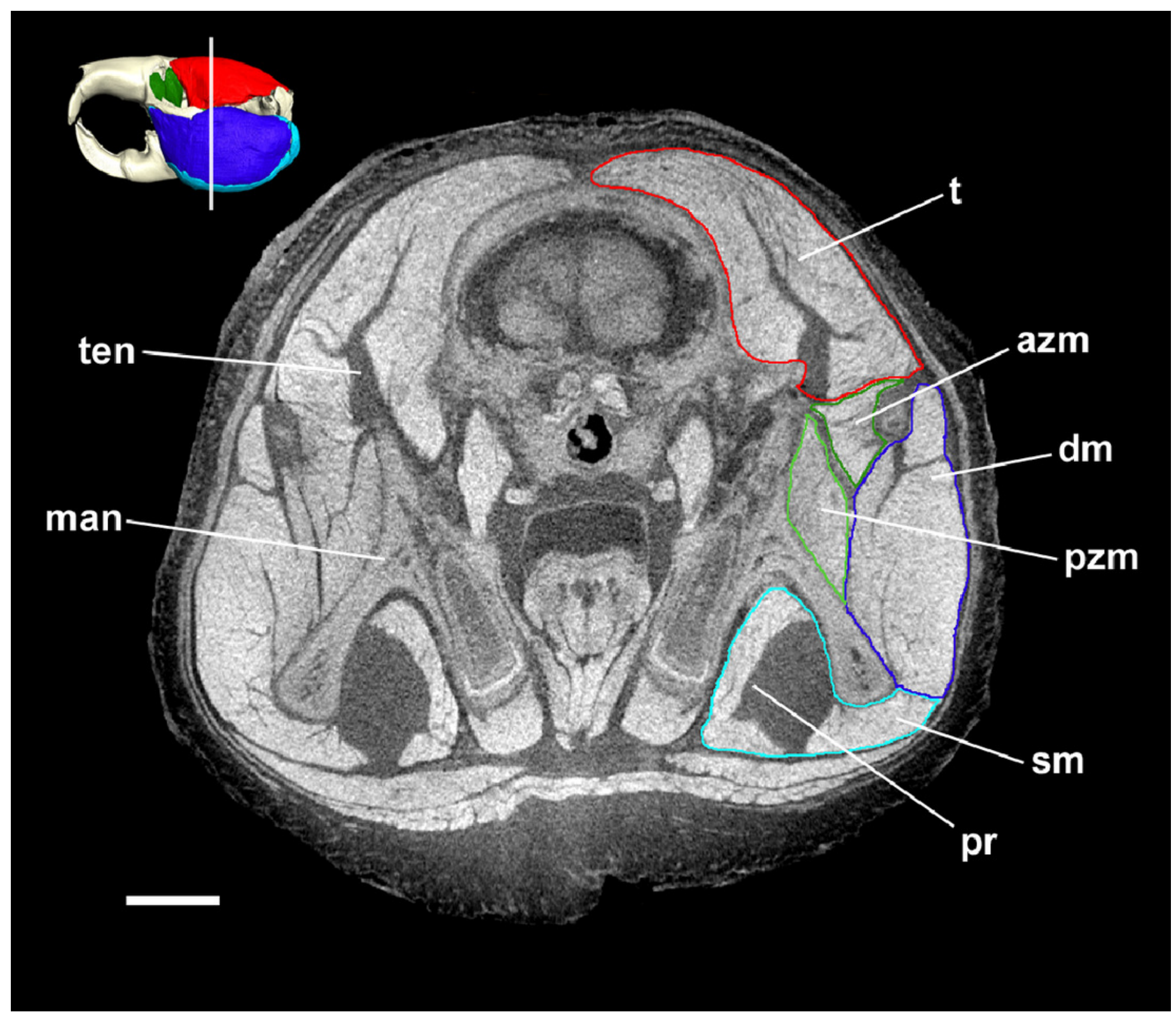




\section{Figure 6}

Temporalis and zygomaticomandibularis muscles of Bathyergidae.

Left lateral view of a 3D reconstruction of the cranium, mandible, temporalis and zygomaticomandibularis of: A, Bathyergus suillus; B, Georychus capensis; C, Cryptomys hottentotus; D, Fukomys mechowi; E, Heliophobius argenteocinereus. Abbreviations: azm, anterior zygomaticomandibularis; iozm, infraorbital portion of the zygomaticomandibularis; pzm, posterior zygomaticomandibularis; t, temporalis. Scale bar $=5 \mathrm{~mm}$.
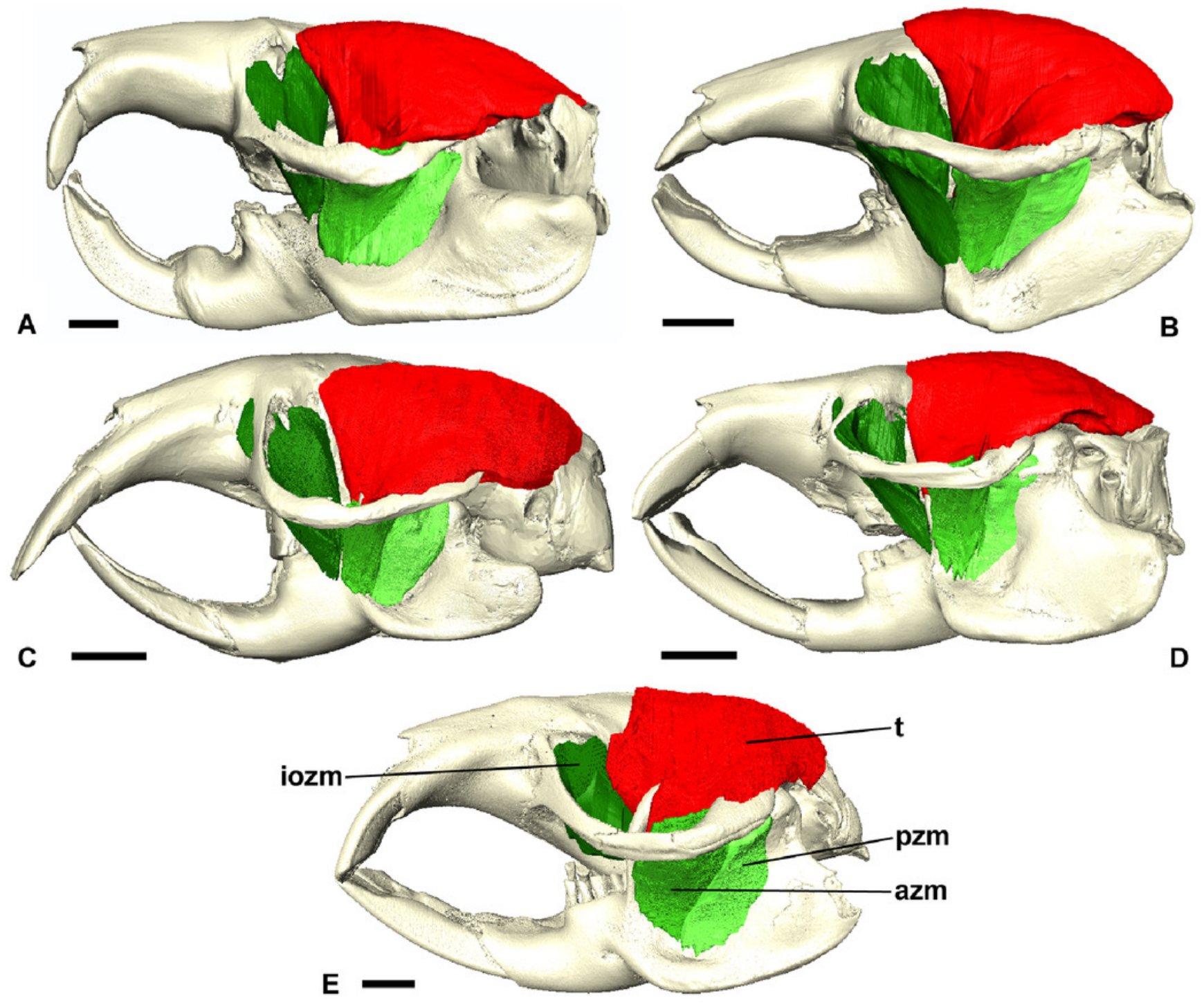


\section{Figure 7}

Transverse diceCT slice of Cryptomys hottentotus.

MicroCT slice through the head of Cryptomys hottentotus stained with iodine potassium iodide. Abbreviations: iozm, infraorbital portion of zygomaticomandibularis (dark green); on, optic nerve; $t$, temporalis (red). White line on 3D reconstruction shows position of slice. Scale bar $=5 \mathrm{~mm}$. 


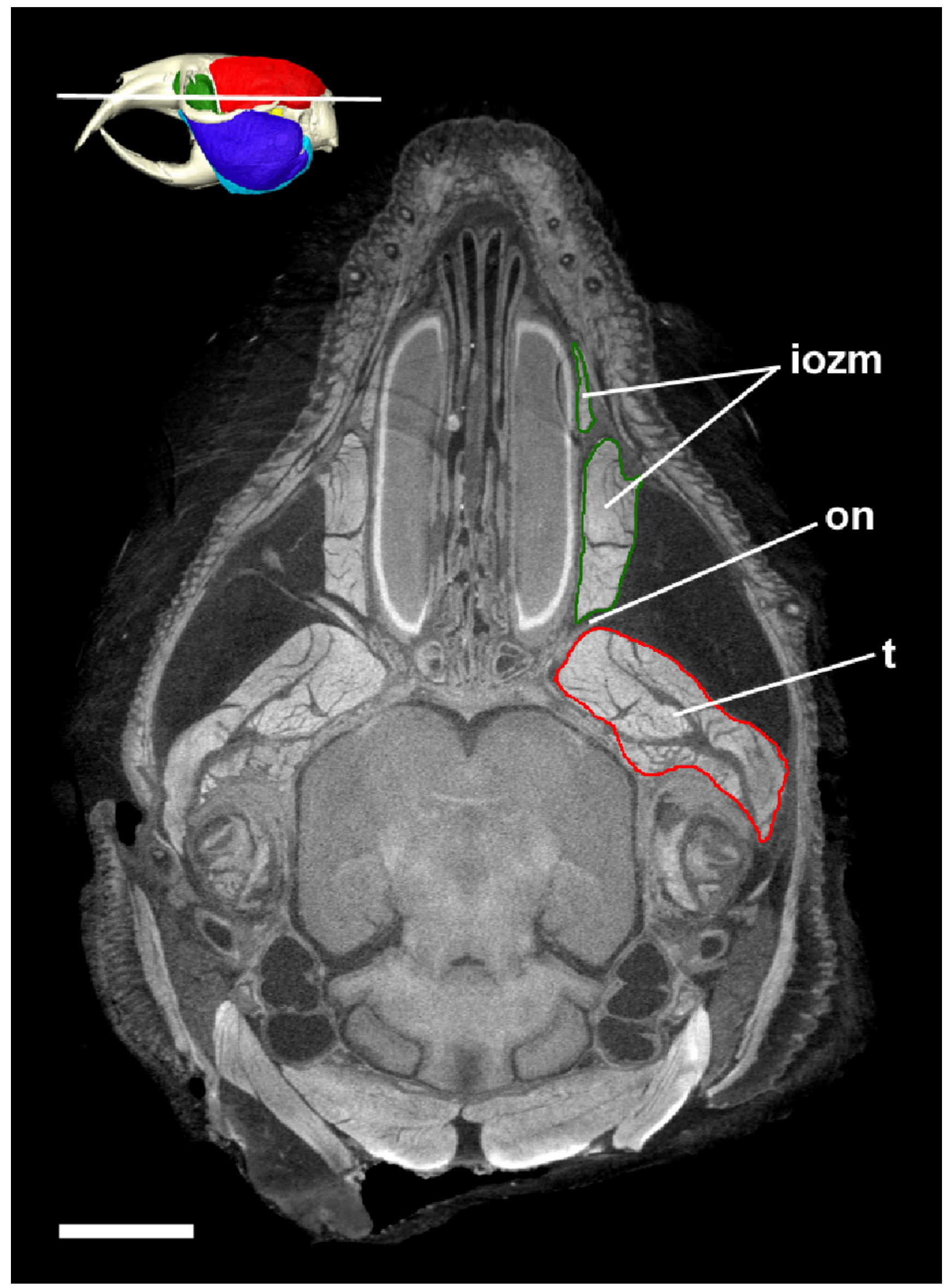

